\title{
Birth Size as a Determinant of Cardiometabolic Risk Factors in Children
}

\author{
Henrikki Nordman Jarmo Jääskeläinen Raimo Voutilainen \\ Department of Pediatrics, University of Eastern Finland and Kuopio University Hospital, Kuopio, Finland
}

\section{Keywords}

Birth weight · Cardiovascular · Childhood - Large for gestational age $\cdot$ Macrosomia $\cdot$ Small for gestational age

\begin{abstract}
The association between birth size and cardiometabolic disease risk may be U-shaped. Being born small for gestational age (SGA) has a definitive association with later cardiovascular risk, but the impact of being born large for gestational age (LGA) on cardiometabolic health is more controversial. In addition to birth size, early postnatal growth pattern and later weight gain affect cardiometabolic risk in adulthood. Most SGA-born children have catch-up and LGA-born children have catch-down growth during the first years of life. The extent of this early compensatory growth may contribute to the adverse health outcomes. Both SGA- and LGAborn children are at an increased risk for overweight and obesity. This may have a long-term impact on cardiometabolic health as overweight tends to track to adulthood. Other cardiometabolic risk factors, including alterations in glucose metabolism, dyslipidemia, hypertension, and lowgrade inflammation are associated with birth weight. Many of these risk factors are related to overweight or adverse fat distribution. Since later cardiometabolic risk is often medi-
\end{abstract}

(c) 2020 S. Karger AG, Basel

www.karger.com/hrp

Karger ated by early growth pattern and later overweight in SGA and LGA children, it is important to focus on staying normal weight throughout life. Hence, effective interventions to reduce cardiometabolic risk in LGA and SGA children should be developed.

c) 2020 S. Karger AG, Basel

\section{Introduction}

In late 1980s, Barker and Osmond [1] suggested that poor nutrition in early childhood increases the risk of cardiovascular disease (CVD) in adulthood. A couple of years later in 1990, Barker [2] described a hypothesis, known as Barker hypothesis, proposing that poor intrauterine growth caused by fetal undernutrition was also associated with increased prevalence of CVD in adulthood.

The impact of birth size on later cardiometabolic health is acknowledged especially with low $[3,4]$ but also increasingly with high birth weight $[5,6]$. The relationship between birth size and cardiometabolic risk has been suggested to be U-shaped, and some cardiovascular risk factors are present as early as in prepuberty [7, 8]. Many of these alterations are weight-related in large for gestational age (LGA) children. The trend of cardiometabolic 
risk is upwards as the proportional share of high birth weight newborns and the prevalence of childhood overweight and obesity have both been rising in the recent past $[9,10]$.

Later cardiometabolic health is affected by early growth and childhood overweight $[11,12]$. The majority of small for gestational age (SGA) children are compensating the restricted intrauterine growth by early catch-up growth and correspondingly, LGA children are seeking their natural genetic growth patterns by catch-down growth. Catch-up growth (especially in weight) has been demonstrated to increase cardiometabolic risk factors, including overweight, obesity, and insulin resistance, already in childhood [11,13] independently of birth weight [14]. A recent systematic review suggests that catch-up growth may have a bigger role in later cardiometabolic risk than low birth weight alone [15]. However, this compensatory growth has also positive effects in SGA children, such as increased adult height and better cognitive capacity [11]. Deceleration in growth velocity in early years could be advantageous in LGA children for retaining normal weight [16]. Absence of this catch-down growth seems to increase the risk for adverse cardiometabolic outcomes in young LGA-born adults [12].

The metabolic syndrome is a cluster of cardiovascular risk factors, including obesity, alterations in glucose-insulin metabolism, dyslipidemia, and hypertension. An estimation of its prevalence in obese children and adolescents rises up to $39 \%$ depending on the definition used. Obesity in children and adolescents, which is associated with other cardiometabolic risk factors, is becoming more common [17]. Some of the cardiometabolic risk factors present in childhood are prone to track to adulthood [18, 19]. The increasing prevalence of overweight and obesity is a global health risk, and the challenge is to intervene cardiometabolic risk factors properly at the right time most commonly by lifestyle interventions. The efficacy of the interventions seems to be most effective when started early [17].

Birth size, growth trajectories, childhood overweight, and increasing obesity have an impact on cardiometabolic health in childhood and later life. Clinical outcomes of cardiometabolic disease are not visible yet in mid-childhood, but the risk factors are. In this mini review, we focus on the impact of birth size on cardiometabolic risk factors in children. The similarities and differences in cardiometabolic health between LGA and SGA children as well as the future impact of being born LGA or SGA on cardiometabolic risk are also discussed. Recognizing these risk factors is crucial for prevention programs in childhood.

\section{Definitions and Determinants}

SGA and LGA are defined by anthropometrics at birth, and the reference for the birth measures used should be relevant to the studied population. SGA and LGA are commonly defined as gestation- and gender-specific birth weight or length $<-2.0$ and $>+2.0$ standard deviation scores (SDS), being equivalent to $<2.3$ and $>97.7$ percentiles, but also birth weight $<10$ th and $>90$ th percentile, respectively, have been used. The cutoff points based on \pm 2.0 SDS may identify better those term infants who need continuing growth evaluation [20]. Using the definitions of the 10th percentile for SGA and 90th percentile for LGA is relevant in neonatology to evaluate morbidity and mortality $[4,21]$. Intrauterine growth restriction is often incorrectly used as a synonym for SGA, but intrauterine growth restriction refers to a state where the fetus cannot achieve its growth potential due to some underlying pathophysiological process [3]. A consensus definition of growth restriction in the newborn was recently presented [22]; this definition was built on the previously established antenatal definition of fetal growth restriction. Low birth weight, very low birth weight, and extremely low birth weight are defined as birth weight $<2,500,<1,500$, and $<1,000 \mathrm{~g}$, respectively [23]. Macrosomia refers to birth weight independent of gestational age and is most widely defined as birth weight $>4,000 \mathrm{~g}$. Still, no consensus agreement on the diagnostic threshold of macrosomia exists [24]. The heterogenous definitions may have an impact on discordant findings between birth size and future cardiometabolic risk.

Growth velocity in weight or height during early life is often accelerated in SGA and decelerated in LGA children. Up to $90 \%$ of SGA children have catch-up growth by the age of 2 years $[11,20]$, whereas $29-81 \%$ of LGA children have catch-down growth $[12,16,25]$. The definitions of early catch-up and catch-down growth vary [26]. The cutoff point for considerable change in growth can be determined as percentiles or SDS. The age intervals used vary from few months up to young adulthood [26], although most variation in growth velocity occurs in the first year of life [11]. The most commonly used definition for rapid growth in obesity-related studies was a higher than 0.67 SDS change in weight for age between 2 different ages in childhood [26].

The factors associated with being born SGA are often classified as fetal, uteroplacental, and maternal (Table 1) and those with being born LGA as fetal and maternal (Table 2). In this mini review, genetic disorders and syndromes affecting birth size are not discussed. Fetal growth is strongly affected by maternal body size. A growing fetus 
Table 1. Factors associated with an increased incidence of being born SGA or with IUGR (modified from [3, 4, 106])

\begin{tabular}{l} 
Fetal \\
Chromosomal abnormalities \\
Genetic diseases \\
Intrauterine infections \\
Uteroplacental \\
Structural placental factors \\
Reduced blood flow \\
Placenta previa \\
Placental abruption \\
Maternal \\
Demographic factors \\
Delivery at age $<16$ or $>35$ yr \\
Maternal body size \\
$\quad$ Low height and pre-pregnancy BMI \\
Low pregnancy BMI with poor gestational weight gain \\
Maternal and paternal race \\
Primi-/nulliparity \\
Multiple pregnancy \\
Previous delivery of an SGA infant \\
Low socioeconomic status \\
Medical conditions \\
Malnutrition \\
Substance use/abuse \\
Smoking \\
Alcohol \\
Illicit drugs \\
Therapeutic drugs \\
\hline
\end{tabular}

SGA, small for gestational age; IUGR, intrauterine growth restriction.

is dependent on the placenta and disturbances of placental function are related to small birth size. Maternal malnutrition, low pre-pregnancy BMI, and poor gestational weight gain have been shown to lower birth weight. Several maternal diseases as well as substance use or abuse are associated with an increased incidence of infants being born SGA $[3,4]$. In LGA-born children, a common reason for excess adipose tissue in fetuses is maternal hyperglycemia that leads to fetal hyperinsulinemia [27], which may be present also in well-balanced gestational diabetes [28]. In addition, maternal pre-pregnancy obesity and excess gestational weight gain without diabetes are associated with high birth weight $[29,30]$. In a recent study, late-pregnancy dysglycemia predisposed the offspring of obese, gestational diabetes-negative mothers to increased BMI at age 4 years [31].

\section{Overweight and Obesity}

The prevalence of overweight and obesity among children and adolescents has increased along with adults.
Table 2. Factors associated with an increased incidence of being born LGA [24, 107, 108]

\author{
Fetal \\ Genetic, racial, and ethnic factors \\ Gestational age $>40$ weeks \\ Male fetus \\ Genetic or chromosomal disorders \\ Congenital hyperinsulinemia \\ Tumors \\ Maternal \\ Maternal body size \\ Maternal pre-pregnancy obesity \\ Excess gestational weight gain \\ Tall maternal height \\ Diabetes mellitus \\ Type I and II \\ Gestational diabetes or MODY \\ History of macrosomia \\ Multiparity
}

MODY, maturity onset diabetes of the young; LGA, large for gestational age.

This alarming trend has been seen in most developed countries and in urban areas of several low-income countries during the last decades as the worldwide obesity has almost tripled since 1975, and is still rising [32]. The number of overweight and obese children aged $0-5$ years was 40 million globally in 2018 [32], and it is predicted to increase to 70 million by 2025 [33]. In older children and adolescents (aged 5-17 years), the corresponding number was 224 million in 2013 and predicted to be 268 million by 2025 [34].

The World Health Organization (WHO) defines overweight and obesity in children younger than 5 years as weight-for-height greater than 2 and 3 SD above the WHO Child Growth Standards median, respectively, and in older children and adolescents as BMI for age greater than 1 and 2 SD above the WHO Growth Reference median [32]. Obesity definition based on weight-for-height curves represents the weight distribution in population that will eventually shift to right due to the secular trend. Still, the classifications of childhood overweight and obesity are not unanimous [35]. The International Obesity Task Force references for overweight and obesity equate adult BMI values of 25 and $30 \mathrm{~kg} / \mathrm{m}^{2}$, respectively [36]. Also, sex- and age-specific BMI between 85th and 95th percentile and over 95th percentile are regarded as overweight and obesity, respectively [37].

Overweight and obesity are independent risk factors for adult cardiometabolic disease [38], but they are also 
associated with other cardiometabolic risk factors detected already in childhood, such as high blood pressure, liver steatosis, dyslipidemia, adverse glucose metabolism, and increased carotid intima-media thickness (IMT) [39]. The cardiometabolic risk is increased by the severity of obesity [40]. It has been estimated that $6-39 \%$ of obese children and adolescents have the metabolic syndrome, which increases morbidity and mortality if tracking to adulthood [17].

The later risk for obesity has been suggested to be elevated in both SGA- and LGA-born children, and the trend is similar in adults $[3,6,25]$, although a large metaanalysis suggested that low birth weight might decrease the long-term risk for overweight among persons aged 1-75 years, independently of geographic origin [41]. In SGA children, the decreased risk for overweight could be explained by their tendency to lower lean mass; however, rapid early weight gain predisposes to visceral adiposity. Overweight and obesity may not be visible in young SGAborn children but develop later [25]. This is supported by previous studies reporting the association between small birth size and overweight in adolescents and adults [42]. In addition, several variables, including a genetic component, play a role in later obesity in low birth weight children [43]. However, it is important to recognize that SGA-born children with catch-up growth may develop visceral adiposity without overweight or obesity already prepubertally [44]. In children born LGA, fetal overnutrition and genotype expose children to overweight and obesity, and the risk of overweight is augmented by inadequate catch-down growth [12]. Childhood overweight and obesity create a risk for later cardiometabolic disturbances by tracking from childhood to adolescence and adulthood $[18,45]$.

\section{Glucose and Insulin}

The association between low and high birth weight and the elevated risk of type 2 diabetes has been demonstrated in both children and adults $[6,7,46]$. Compared to appropriate for gestational age (AGA)-born children, reported ORs $(95 \% \mathrm{CI})$ for type 2 diabetes are 2.91 (1.256.76) and 1.78 (1.04-3.06) in SGA- and LGA-born schoolaged children, respectively [7]. In adults, low birth weight may have a stronger impact on the risk of type 2 diabetes than high birth weight (OR [95\% CI] 0.75 [0.70-0.81]) per kilogram of increase in birth weight [46]. However, there was some heterogeneity between populations in this systematic review, mostly explained by 3 studies ( 2 of them in native North American populations and 1 in the Saskatchewan general population) where the associations were U-shaped. In addition, the inverse association between birth weight and type 2 diabetes strengthened to OR (95\% CI) 0.70 (0.65-0.76) when adjusted for current BMI [46]. However, the risk increases when birth weight is over $4 \mathrm{~kg}(\mathrm{OR}$ [95\% CI] 1.35 [0.67-2.72]) [46] or 3 SDS (hazard ratio [95\% CI] 5.44 [2.70-10.96] in males) [6]. Overweight and obesity, especially central, associate with hyperinsulinemia $[47,48]$, but glucose metabolism is also altered independently of overweight at least in SGA children [49]. In short prepubertal SGA children, age- and BMI-adjusted insulin sensitivity levels were $38 \%$ lower than those of short AGA controls assessed by intravenous glucose tolerance test. For maintaining normal glucose tolerance, SGA children compensated reduced insulin sensitivity by almost tripling the acute insulin response [49]. To evaluate glucose-insulin-metabolism, different indexes can be calculated, such as insulinogenic index (index of $\beta$-cell function), homeostasis model assessment for insulin resistance, and disposition index (index of $\beta$-cell compensation). In obese children, being born SGA or LGA seemed to increase insulin resistance compared to AGA controls, but decreased insulinogenic and disposition indexes were demonstrated only in SGA children [50]. In addition, some studies have indicated increases in insulin levels and insulin resistance, but not in fasting glucose levels in SGA- and LGA-born children compared to AGA-born ones [8,51].

In addition to birth weight, accelerated early weight gain, seen especially in SGA children, increases the risk of insulin resistance in childhood and young adulthood [11, 52]. There is evidence that insulin sensitivity could be better and insulin levels lower in children with catch-down growth than in children with rapid postnatal growth [53].

\section{Lipids}

The impact of birth weight on lipid levels in childhood is somewhat controversial. It seems that low birth weight is associated with adverse lipid levels $[54,55]$ and poor catch-up growth in height may increase the risk of high total cholesterol (OR [95\% CI] 13.8 [2.0-97.5]) [54]. In LGA children, the impact of birth size is not as clear as in SGA children. At some level, high birth weight associates with unfavorable lipid profile (adjusted correlation coefficients $0.27-0.30$ between birth weight and total/LDL cholesterol) [56], but overweight and obesity may be more important mediators in dyslipidemia. Dyslipidemia has an important impact on future cardiometabolic health $[57,58]$. In adults, both low and high birth weights have been associated with dyslipidemia $[6,59]$. 


\section{Blood Pressure}

Elevated blood pressure tracking from childhood to adulthood increases the risk for CVD in adulthood but is fortunately reduceable by early intervention $[19,60,61]$. Current weight is a major determinant of childhood hypertension. A part of the association between birth weight and blood pressure in childhood is derived from the impact of birth weight on childhood overweight. Still, some studies have shown an independent association between birth weight and blood pressure in children and adolescents $[62,63]$.

Being born SGA and rapid postnatal growth have been reported widely to associate with elevated systolic blood pressure (SBP) in children, adolescents, and adults [64]. A study of a large cohort of Chinese children showed a 4.3-fold increased risk for hypertension in children born small $(<2,500 \mathrm{~g})$ with their childhood weights $>22.7 \mathrm{~kg}$ at the age of 3-6 years compared to those born with normal weight $(2,500-4,000 \mathrm{~g})$ and having their childhood weights $<22.7 \mathrm{~kg}$ at $3-6$ years of age [65]. In addition, ORs (95\% CI) for adjusted (catch-up growth, height, and father's occupation) association between birth weight $\mathrm{Z}$-score and the risk of hypertension at the age of 5 years or older were $5.67(3.83-8.39)$ in boys and 2.58 (1.79-3.73) in girls [65]. However, there were limitations in that study, as only $1 \%$ of the studied children were born small and the joint effect of birth weight and current weight was not adjusted for height. It is noticeable that early catch-up growth seems to increase the risk of childhood hypertension also independently $[64,65]$. Maternal preeclampsia is associated with increased SBP and diastolic blood pressure in the offspring already in childhood, and being born SGA after a preeclamptic pregnancy increased the risk of higher SBP (OR [95\% CI] 8.7 [1.3-57]) [66, 67]. Being born LGA or with high birth weight increased the risk of elevated blood pressure in adolescents [68]. In 7-year-old LGAborn children, the risk of hypertension associated with the lack of catch-down growth (and subsequent obesity) [16]. Overall, the evidence of an independent impact of high birth weight on hypertension is not as strong as that of low birth weight. Gender and different ethnicities could explain some of this variation. A large study of children and adolescents demonstrated recently a Ushaped association between the prevalence of high SBP and birth weight in Hispanic children, whereas in whites, the association was inversely linear, and blacks did not show any significant association. Also, the U-shaped trend in ORs of high SBP was only seen in Hispanic boys, not in girls [69].

\section{Endothelial Function and Vascular Changes}

Endothelial dysfunction precedes structural atherosclerotic changes, and it can be assessed noninvasively by flow-mediated dilation, which has been reported to predict cardiovascular events [70]. Low birth weight has been shown to associate with impaired endothelial function in childhood [71-73] and adulthood [74].

Carotid IMT is associated with atherosclerotic vascular changes and predicts the cardiovascular risk [75]. In SGA children, increased carotid IMT has been reported already at the age of 3-6 years, and in the combined SGA and AGA population, excessive weight gain between 3 and 6 years of age was an independent predictor of carotid IMT [76]. In addition, obesity-related increase of carotid IMT can be seen already in children and adolescents [75], and it remains until adulthood, if obesity continues [77].

\section{Adrenal Function}

The adrenocortical maturation in mid-childhood, adrenarche, is regarded premature when clinical signs appear in the presence of elevated serum dehydroepiandrosterone sulfate (DHEAS) levels for age before the age of 8 years in girls and 9 years in boys [78]. Premature adrenarche has been associated with overweight/obesity and adverse glucose and lipid metabolism in both AGAand SGA-born children [79-81]. Still, a recent study did not find an association between high DHEAS levels and adverse cardiometabolic risk factor levels, except higher BMI SDS, in healthy prepubertal primary school children [82]. Low birth weight was associated with higher circulating DHEAS [44, 83] and epinephrine [83] levels in childhood and birth weight had an inverse association with serum DHEAS levels all the way from SGA to LGA children $[84,85]$. There may be a weak association of low birth weight with circulating cortisol levels, but it has been difficult to show convincingly the role of the hypothalamo-pituitary-adrenal axis in the reported epidemiological association between birth size and later CVD [86].

\section{Low-Grade Inflammation}

Atherosclerosis and CVD risk are strongly affected by low-grade inflammation [87]. As the excess adipose tissue produces inflammatory cytokines, it is not surprising that overweight is associated with low-grade inflammation [88], already in prepubertal children [89]. In addition, Seppä et al. [90] showed recently that elevated interleukin-1 receptor antagonist (IL-1Ra) levels might be associated with higher cardiometabolic risk in 12-year-old children. 
Fig. 1. The impact of birth size and interventions on later cardiometabolic health. To reduce the risk for SGA or LGA during pregnancy, interventions should be addressed to maintain proper balance in maternal weight gain and good management of maternal diabetes, to reduce maternal smoking and alcohol consumption, and to treat other maternal medical conditions, including hypertension and severe chronic diseases. In both SGA and LGA children, the change of weight velocity has an essential impact on later adverse cardiometabolic outcomes. Overweight and obesity are related to most cardiometabolic risk factors. Hence, preventing these by regular growth evaluation and early interventions (including family counseling in nutrition, physical activity, and sleep) improve later cardiometabolic health. In addition, pharmacotherapy and bariatric surgery (from adolescence) are occasionally needed if lifestyle counseling alone is not effective enough. SGA, small for gestational age; LGA, large for gestational age.

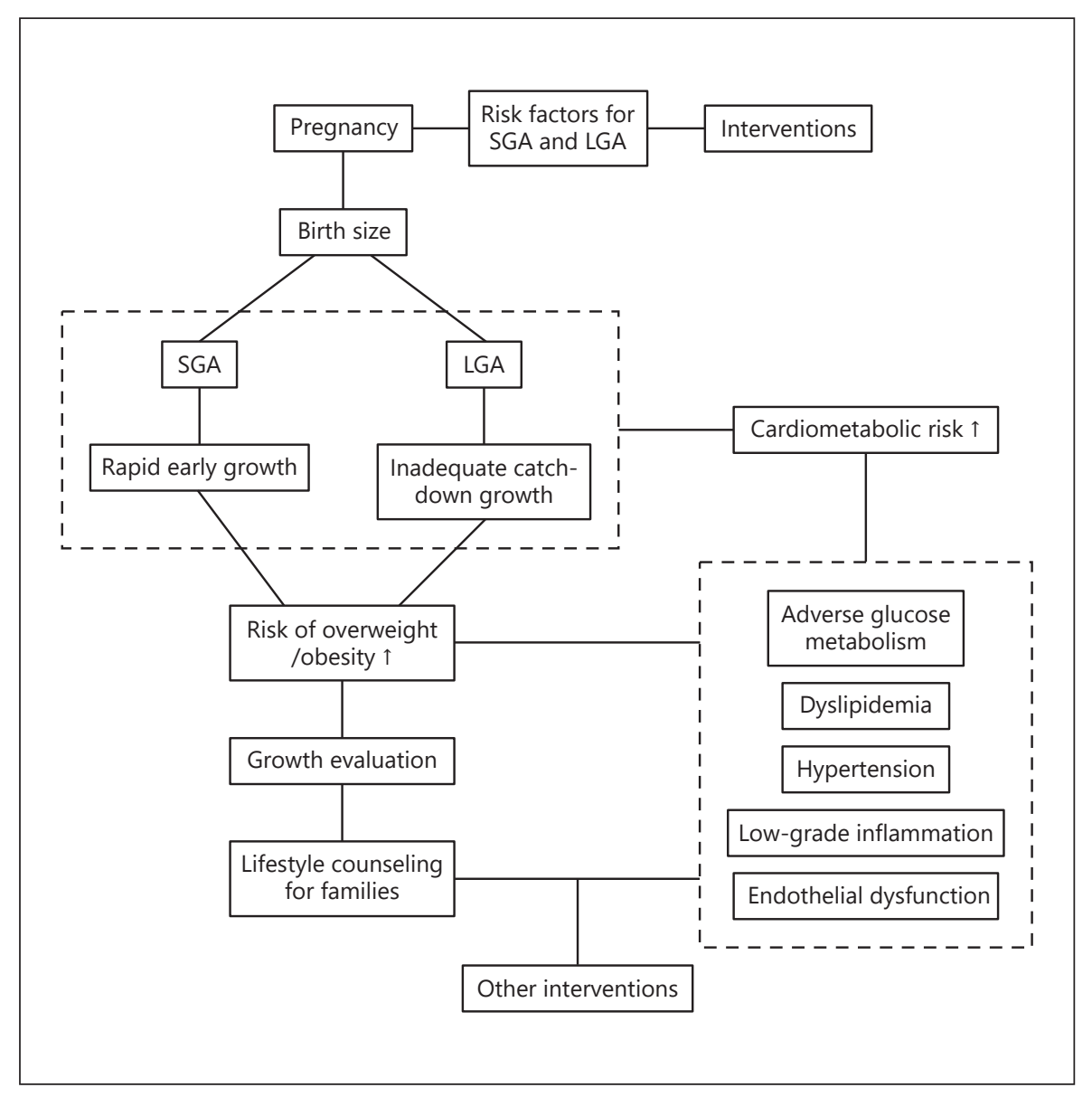

C-reactive protein (CRP) is a widely used inflammatory marker, and its elevated concentrations predict CVD in adults [91]. Elevated serum CRP concentrations have been associated with lower birth weight in both children and adults [92, 93]. Inverse association between birth weight and other inflammatory markers, including fibrinogen and IL-1Ra, have been reported in children and adolescents $[94,95]$. Still, there is some evidence suggesting that also LGA children have increased low-grade inflammation, and decreased tumor necrosis factor (TNF)- $\alpha$ levels were proposed to associate with insulin resistance [96].

\section{Future Aspects}

Traditional cardiometabolic risk factors have been widely reported to associate with birth weight in children and adults [7, 8, 97]. Susceptibility to cardiometabolic disease is a combination of genetics and environment, and the metabolic programming for later diseases, starting before birth and continuing throughout early child- hood growth, has been suggested to explain partly the future risk $[12,98]$. Epigenetic changes (DNA methylation, histone modification, and noncoding RNAs) have been demonstrated to have an important role in the etiology of cardiometabolic disorders [99]. Studies in this field are increasing also in children. A recent study suggests that alterations in DNA methylation of certain imprinted genes at birth are associated with the risk of obesity at 1 and 3 years of age [100], and previously, changes in DNA methylation were associated with severe obesity also in older children [101]. In addition, birth weight has also been associated with epigenetic changes. In 1 study, birth weight was associated with DNA methylation at several $\mathrm{CpG}$ sites at birth, and these changes could be seen partly also in mid-childhood [102]. These results were in concordance with previous studies. When divided in birth weight groups, 1 study did not reveal any differences in genome-wide DNA methylation analysis of umbilical cord tissues between LGA children with catch-down growth and AGA children [103]. 


\section{Conclusion}

Both low and high birth weights have an impact on later cardiometabolic health, and cardiovascular risk factors can be detected already in childhood (Fig. 1). Even though some risk factors originating from the fetal environment cannot be changed after birth, good cardiovascular health can be restored by influencing postnatal risk factors before adulthood [104]. In LGA-born children, overweight and obesity seem to be associated with many of these risk factors, and early catch-down growth would be important for staying normal weight in later life. In SGA children, overweight and obesity may appear later in adolescence or adulthood, and early catch-up growth in weight may contribute to this risk. Contrary to LGA children, cardiometabolic risk is not as much weight-related in SGA children who may have visceral adiposity despite normal weight in childhood.

Many of the cardiometabolic risk factors present in childhood and adolescence track to adulthood. Hence, it is very important to intervene these adverse findings, especially obesity, as soon as they are detected (Fig. 1). Regularly evaluated growth and low-threshold lifestyle coun- seling (in nutrition, physical activity, and sleep) should be provided in child welfare clinics and school health services from birth to adolescence. Since parental obesity and sedentary lifestyle increase the risk of obesity in the offspring [105], counseling should concern the whole family, not just individuals. Also, effective interventions to reduce and treat cardiometabolic risk in SGA and LGA children should be developed.

\section{Conflict of Interest Statement}

The authors have no conflicts of interest to declare.

\section{Funding Sources}

The authors received no specific funding for this work.

\section{Author Contributions}

All authors have contributed to the writing of the manuscript.

\section{References}

1 Barker DJ, Osmond C. Infant mortality, childhood nutrition, and ischaemic heart disease in England and Wales. Lancet. 1986; 1(8489):1077-81.

2 Barker DJ. The fetal and infant origins of adult disease. BMJ. 1990;301(6761):1111.

3 Saenger P, Czernichow P, Hughes I, Reiter EO. Small for gestational age: short stature and beyond. Endocr Rev. 2007;28(2):219-51.

4 Finken MJJ, van der Steen M, Smeets CCJ, Walenkamp MJE, de Bruin C, Hokken-Koelega ACS, et al. Children born small for gestational age: differential diagnosis, molecular genetic evaluation, and implications. Endocr Rev. 2018;39(6):851-94.

5 Boney CM, Verma A, Tucker R, Vohr BR. Metabolic syndrome in childhood: association with birth weight, maternal obesity, and gestational diabetes mellitus. Pediatrics. 2005. 115(3):e290-6.

6 Johnsson IW, Haglund B, Ahlsson F, Gustafsson J. A high birth weight is associated with increased risk of type 2 diabetes and obesity. Pediatr Obes. 2015;10(2):77-83.

7 Wei JN, Sung FC, Li CY, Chang CH, Lin RS, Lin CC, et al. Low birth weight and high birth weight infants are both at an increased risk to have type 2 diabetes among schoolchildren in Taiwan. Diabetes Care. 2003;26(2):343-8.
8 Evagelidou EN, Giapros VI, Challa AS, Cholevas VK, Vartholomatos GA, Siomou EC, et al. Prothrombotic state, cardiovascular, and metabolic syndrome risk factors in prepubertal children born large for gestational age. Diabetes Care. 2010;33(11):2468-70.

9 Surkan PJ, Hsieh CC, Johansson AL, Dickman PW, Cnattingius S. Reasons for increasing trends in large for gestational age births. Obstet Gynecol. 2004;104(4):720-6.

$10 \mathrm{Ng} \mathrm{M}$, Fleming T, Robinson M, Thomson B, Graetz N, Margono C, et al. Global, regional, and national prevalence of overweight and obesity in children and adults during 1980 2013: a systematic analysis for the Global Burden of Disease Study 2013. Lancet. 2014; 384(9945):766-81.

11 Ong KK. Catch-up growth in small for gestational age babies: good or bad? Curr Opin Endocrinol Diabetes Obes. 2007;14(1):30-4.

12 Renom Espineira A, Fernandes-Rosa FL, Bueno AC, de Souza RM, Moreira AC, de Castro $\mathrm{M}$, et al. Postnatal growth and cardiometabolic profile in young adults born large for gestational age. Clin Endocrinol. 2011;75(3):33541.

13 Lurbe E, Aguilar F, Álvarez J, Redon P, Torró MI, Redon J. Determinants of cardiometabolic risk factors in the first decade of life: a longitudinal study starting at birth. Hypertension. 2018;71(3):437-43.
14 Ong KK, Loos RJ. Rapid infancy weight gain and subsequent obesity: systematic reviews and hopeful suggestions. Acta Paediatr. 2006; 95(8):904-8.

15 Kelishadi R, Haghdoost AA, Jamshidi F, Aliramezany $\mathrm{M}$, Moosazadeh $\mathrm{M}$. Low birthweight or rapid catch-up growth: which is more associated with cardiovascular disease and its risk factors in later life? A systematic review and cryptanalysis. Paediatr Int Child Health. 2015;35(2):110-23.

16 Lei X, Zhao D, Huang L, Luo Z, Zhang J, Yu $\mathrm{X}$, et al. Childhood health outcomes in term, large-for-gestational-age babies with different postnatal growth patterns. Am J Epidemiol. 2018;187(3):507-14.

17 Weihe $\mathrm{P}$, Weihrauch-Blüher S. Metabolic syndrome in children and adolescents: diagnostic criteria, therapeutic options and perspectives. Curr Obes Rep. 2019;8(4):472-9.

18 Singh AS, Mulder C, Twisk JW, van Mechelen W, Chinapaw MJ. Tracking of childhood overweight into adulthood: a systematic review of the literature. Obes Rev. 2008;9(5): 474-88.

19 Liang Y, Hou D, Shan X, Zhao X, Hu Y, Jiang $\mathrm{B}$, et al. Cardiovascular remodeling relates to elevated childhood blood pressure: Beijing blood pressure cohort study. Int J Cardiol. 2014;177(3):836-9. 
20 Clayton PE, Cianfarani S, Czernichow P, Johannsson G, Rapaport R, Rogol A. Management of the child born small for gestational age through to adulthood: a consensus statement of the international societies of pediatric endocrinology and the growth hormone research society. J Clin Endocrinol Metab. 2007; 92(3):804-10.

21 Chauhan SP, Rice MM, Grobman WA, Bailit J, Reddy UM, Wapner RJ, et al. Neonatal morbidity of small- and large-for-gestational-age neonates born at term in uncomplicated pregnancies. Obstet Gynecol. 2017;130(3):511-9.

22 Beune IM, Bloomfield FH, Ganzevoort W, Embleton ND, Rozance PJ, van WassenaerLeemhuis AG, et al. Consensus based definition of growth restriction in the newborn. J Pediatr. 2018;196:71-6.e1.

23 World Health Organization. International statistical classification of diseases and related health problems, 10th revision, Fifth edition (2015). 2016. Available from: http://www. who.int/iris/handle/10665/246208.

24 Langer O. Fetal macrosomia: etiologic factors. Clin Obstet Gynecol. 2000;43(2):283-97.

25 Taal HR, Vd Heijden AJ, Steegers EA, Hofman A, Jaddoe VW. Small and large size for gestational age at birth, infant growth, and childhood overweight. Obesity. 2013;21(6): 1261-8.

26 Monteiro PO, Victora CG. Rapid growth in infancy and childhood and obesity in later life: a systematic review. Obes Rev. 2005;6(2): 143-54.

27 Kc K, Shakya S, Zhang H. Gestational diabetes mellitus and macrosomia: a literature review. Ann Nutr Metab. 2015;66(Suppl 2):14-20.

28 Castillo-Castrejon M, Powell TL. Placental nutrient transport in gestational diabetic pregnancies. Front Endocrinol. 2017;8:306.

29 Faucher MA, Barger MK. Gestational weight gain in obese women by class of obesity and select maternal/newborn outcomes: a systematic review. Women Birth. 2015;28(3):e70-9.

30 Baugh N, Harris DE, Aboueissa AM, Sarton C, Lichter E. The impact of maternal obesity and excessive gestational weight gain on maternal and infant outcomes in Maine: analysis of pregnancy risk assessment monitoring system results from 2000 to 2010. J Pregnancy. 2016;2016:5871313.

31 Gomes D, von Kries R, Delius M, Mansmann U, Nast M, Stubert M, et al. Late-pregnancy dysglycemia in obese pregnancies after negative testing for gestational diabetes and risk of future childhood overweight: an interim analysis from a longitudinal mother-child cohort study. PLoS Med. 2018;15(10):e1002681.

32 World Health Organization. Obesity and overweight. 2018. Available from: http:// www.who.int/en/news-room/fact-sheets/detail/obesity-and-overweight.

33 World Health Organization. Second meeting of the commission on ending childhood obesity (ECHO). 2015. Available from: https:// www.who.int/end-childhood-obesity/news/ echo-second-meeting.
34 Lobstein T, Jackson-Leach R. Planning for the worst: estimates of obesity and comorbidities in school-age children in 2025. Pediatr Obes. 2016;11(5):321-5.

35 Wang Y, Lobstein T. Worldwide trends in childhood overweight and obesity. Int J Pediatr Obes. 2006;1(1):11-25.

36 Cole TJ, Lobstein T. Extended international (IOTF) body mass index cut-offs for thinness, overweight and obesity. Pediatr Obes. 2012; 7(4):284-94.

37 US Preventive Services Task Force; Grossman DC, Grossman DC, Bibbins-Domingo K, Curry SJ, Barry MJ, Davidson KW, et al. Screening for obesity in children and adolescents: US preventive services task force recommendation statement. JAMA. 2017; 317(23):2417-26.

38 Ginter E, Simko V. Becoming overweight: is there a health risk? Bratisl Lek Listy. 2014; 115(9):527-31.

39 Friedemann C, Heneghan C, Mahtani K, Thompson M, Perera R, Ward AM. Cardiovascular disease risk in healthy children and its association with body mass index: systematic review and meta-analysis. BMJ. 2012;345: e4759.

40 Bass R, Eneli I. Severe childhood obesity: an under-recognised and growing health problem. Postgrad Med J. 2015;91(1081):639-45.

41 Schellong K, Schulz S, Harder T, Plagemann A. Birth weight and long-term overweight risk: systematic review and a meta-analysis including 643,902 persons from 66 studies and 26 countries globally. PLoS One. 2012; 7(10): 47776

42 Tam CH, Wang Y, Luan J, Lee HM, Luk AO, Tutino GE, et al. Non-linear relationship between birthweight and cardiometabolic risk factors in Chinese adolescents and adults. Diabet Med. 2015;32(2):220-5.

43 Morgan AR, Thompson JM, Murphy R, Black PN, Lam WJ, Ferguson LR, et al. Obesity and diabetes genes are associated with being born small for gestational age: results from the Auckland birthweight collaborative study. BMC Med Genet. 2010;11:125.

44 Ibáñez L, Lopez-Bermejo A, Díaz M, Suárez L, de Zegher F. Low-birth weight children develop lower sex hormone binding globulin and higher dehydroepiandrosterone sulfate levels and aggravate their visceral adiposity and hypoadiponectinemia between six and eight years of age. J Clin Endocrinol Metab. 2009;94(10):3696-9.

45 Geserick M, Vogel M, Gausche R, Lipek T, Spielau U, Keller E, et al. Acceleration of BMI in early childhood and risk of sustained obesity. N Engl J Med. 2018;379(14):1303-12.

46 Whincup PH, Kaye SJ, Owen CG, Huxley R, Cook DG, Anazawa S, et al. Birth weight and risk of type 2 diabetes: a systematic review. JAMA. 2008;300(24):2886-97.
47 Freedman DS, Srinivasan SR, Burke GL, Shear CL, Smoak CG, Harsha DW, et al. Relation of body fat distribution to hyperinsulinemia in children and adolescents: the Bogalusa heart study. Am J Clin Nutr. 1987; 46(3):403-10.

48 Whincup PH, Cook DG, Adshead F, Taylor SJ, Walker M, Papacosta O, et al. Childhood size is more strongly related than size at birth to glucose and insulin levels in 10-11-yearold children. Diabetologia. 1997;40(3):31926.

49 Arends NJ, Boonstra VH, Duivenvoorden HJ, Hofman PL, Cutfield WS, Hokken-Koelega AC. Reduced insulin sensitivity and the presence of cardiovascular risk factors in short prepubertal children born small for gestational age (SGA). Clin Endocrinol. 2005;62(1): 44-50.

50 Brufani C, Grossi A, Fintini D, Tozzi A, Nocerino V, Patera PI, et al. Obese children with low birth weight demonstrate impaired beta-cell function during oral glucose tolerance test. J Clin Endocrinol Metab. 2009; 94(11):4448-52.

51 Sancakli O, Darendeliler F, Bas F, Gokcay G, Disci R, Aki S, et al. Insulin, adiponectin, IGFBP-1 levels and body composition in small for gestational age born non-obese children during prepubertal ages. Clin Endocrinol. 2008;69(1):88-92.

52 Woo JG. Infant growth and long-term cardiometabolic health: a review of recent findings. Curr Nutr Rep. 2019;8(1):29-41.

53 Ong KK, Petry CJ, Emmett PM, Sandhu MS, Kiess W, Hales CN, et al. Insulin sensitivity and secretion in normal children related to size at birth, postnatal growth, and plasma insulin-like growth factor-I levels. Diabetologia. 2004;47(6):1064-70.

54 Tenhola S, Martikainen A, Rahiala E, Herrgård E, Halonen P, Voutilainen R. Serum lipid concentrations and growth characteristics in 12-year-old children born small for gestational age. Pediatr Res. 2000;48(5):623628.

55 Mullett MD, Cottrell L, Lilly C, Gadikota K, Dong L, Hobbs G, et al. Association between birth characteristics and coronary disease risk factors among fifth graders. J Pediatr. 2014; 164(1):78-82.

56 Lin XH, Wu DD, Gao L, Zhang JY, Pan HT, Wang $\mathrm{H}$, et al. Altered DNA methylation in neonates born large-for-gestational-age is associated with cardiometabolic risk in children. Oncotarget. 2016;7(52):86511-21.

$57 \mathrm{Lu} \mathrm{H}$, Daugherty A. Atherosclerosis. Arterioscler Thromb Vasc Biol. 2015;35(3):485-91.

58 Frohlich J, Al-Sarraf A. Cardiovascular risk and atherosclerosis prevention. Cardiovasc Pathol. 2013;22(1):16-8.

59 Barker DJ, Hales CN, Fall CH, Osmond C, Phipps K, Clark PM. Type 2 (non-insulin-dependent) diabetes mellitus, hypertension and hyperlipidaemia (syndrome X): relation to reduced fetal growth. Diabetologia. 1993;36(1): 62-7. 
60 Kelly RK, Thomson R, Smith KJ, Dwyer T, Venn A, Magnussen CG. Factors affecting tracking of blood pressure from childhood to adulthood: the childhood determinants of adult health study. J Pediatr. 2015;167(6): 1422-8.e2.

61 Chobanian AV, Bakris GL, Black HR, Cushman WC, Green LA, Izzo JL Jr, et al. The seventh report of the joint national committee on prevention, detection, evaluation, and treatment of high blood pressure: the JNC 7 report. JAMA. 2003;289(19):2560-72.

62 Chiolero A, Paradis G, Kaufman JS. Assessing the possible direct effect of birth weight on childhood blood pressure: a sensitivity analysis. Am J Epidemiol. 2014;179(1):4-11.

63 Huxley R, Neil A, Collins R. Unravelling the fetal origins hypothesis: is there really an inverse association between birthweight and subsequent blood pressure? Lancet. 2002; 360(9334):659-65.

64 Huxley RR, Shiell AW, Law CM. The role of size at birth and postnatal catch-up growth in determining systolic blood pressure: a systematic review of the literature. J Hypertens. 2000;18(7):815-31.

65 Bowers K, Liu G, Wang P, Ye T, Tian Z, Liu $\mathrm{E}$, et al. Birth weight, postnatal weight change, and risk for high blood pressure among Chinese children. Pediatrics. 2011;127(5):e12729.

66 Tenhola S, Rahiala E, Martikainen A, Halonen P, Voutilainen R. Blood pressure, serum lipids, fasting insulin, and adrenal hormones in 12-year-old children born with maternal preeclampsia. J Clin Endocrinol Metab. 2003;88(3):1217-22.

67 Tenhola S, Rahiala E, Halonen P, Vanninen E, Voutilainen R. Maternal preeclampsia predicts elevated blood pressure in 12-year-old children: evaluation by ambulatory blood pressure monitoring. Pediatr Res. 2006;59(2): $320-4$.

68 Kuciene R, Dulskiene V, Medzioniene J. Associations between high birth weight, being large for gestational age, and high blood pressure among adolescents: a cross-sectional study. Eur J Nutr. 2018;57(1):373-81.

69 Sun D, Wang T, Heianza Y, Huang T, Shang $\mathrm{X}, \mathrm{Lv}$ J, et al. Birthweight and cardiometabolic risk patterns in multiracial children. Int J Obes. 2018;42(1):20-7.

70 Sandoo A, van Zanten JJ, Metsios GS, Carroll D, Kitas GD. The endothelium and its role in regulating vascular tone. Open Cardiovasc Med J. 2010;4:302-12.

71 Faienza MF, Brunetti G, Delvecchio M, Zito A, De Palma F, Cortese F, et al. Vascular function and myocardial performance indices in children born small for gestational age. Circ J. 2016;80(4):958-63.

72 Leeson CP, Whincup PH, Cook DG, Donald AE, Papacosta O, Lucas A, et al. Flow-mediated dilation in 9-11-year-old children: the influence of intrauterine and childhood factors. Circulation. 1997;96(7):2233-8.
73 Franco MC, Christofalo DM, Sawaya AL, Ajzen SA, Sesso R. Effects of low birth weight in 8-13-year-old children: implications in endothelial function and uric acid levels. Hypertension. 2006;48(1):45-50.

74 Leeson CP, Kattenhorn M, Morley R, Lucas A, Deanfield JE. Impact of low birth weight and cardiovascular risk factors on endothelial function in early adult life. Circulation. 2001; 103(9): 1264-8.

75 Silva LR, Stefanello JM, Pizzi J, Timossi LS, Leite N. Atherosclerosis subclinical and inflammatory markers in obese and nonobese children and adolescents. Rev Bras Epidemiol. 2012;15(4):804-16.

76 Sebastiani G, Díaz M, Bassols J, Aragonés G, López-Bermejo A, de Zegher F, et al. The sequence of prenatal growth restraint and postnatal catch-up growth leads to a thicker intima-media and more pre-peritoneal and hepatic fat by age 3-6 years. Pediatr Obes. 2016; 11(4):251-7.

77 Juonala M, Magnussen CG, Berenson GS, Venn A, Burns TL, Sabin MA, et al. Childhood adiposity, adult adiposity, and cardiovascular risk factors. N Engl J Med. 2011; 365(20):1876-85.

78 Utriainen P, Laakso S, Liimatta J, Jääskeläinen J, Voutilainen R. Premature adrenarche: a common condition with variable presentation. Horm Res Paediatr. 2015;83(4):221-31.

79 Utriainen P, Jääskeläinen J, Saarinen A, Vanninen E, Mäkitie O, Voutilainen R. Body composition and bone mineral density in children with premature adrenarche and the association of LRP5 gene polymorphisms with bone mineral density. J Clin Endocrinol Metab. 2009;94(11):4144-51.

80 Neville KA, Walker JL. Precocious pubarche is associated with SGA, prematurity, weight gain, and obesity. Arch Dis Child. 2005;90(3): 258-61.

81 Utriainen $\mathrm{P}$, Jääskeläinen J, Romppanen J, Voutilainen R. Childhood metabolic syndrome and its components in premature adrenarche. J Clin Endocrinol Metab. 2007; 92(11):4282-5

82 Mäntyselkä A, Lindi V, Viitasalo A, Eloranta AM, Ågren J, Väisänen S, et al. Associations of dehydroepiandrosterone sulfate with cardiometabolic risk factors in prepubertal children. J Clin Endocrinol Metab. 2018;103(7): 2592-600.

83 Tenhola S, Martikainen A, Rahiala E, Parviainen M, Halonen P, Voutilainen R. Increased adrenocortical and adrenomedullary hormonal activity in 12-year-old children born small for gestational age. J Pediatr. 2002; 141(4):477-82.

84 Ong KK, Potau N, Petry CJ, Jones R, Ness AR, Honour JW, et al. Opposing influences of prenatal and postnatal weight gain on adrenarche in normal boys and girls. J Clin Endocrinol Metab. 2004;89(6):2647-51.
85 Nordman H, Voutilainen R, Antikainen L, Jäs̈keläinen J. Prepubertal children born large for gestational age have lower serum DHEAS concentrations than those with a lower birth weight. Pediatr Res. 2017;82(2): 285-9.

86 van Montfoort N, Finken MJ, le Cessie S, Dekker FW, Wit JM. Could cortisol explain the association between birth weight and cardiovascular disease in later life? A meta-analysis. Eur J Endocrinol. 2005;153(6):811-7.

87 Hansson GK, Hermansson A. The immune system in atherosclerosis. Nat Immunol. 2011;12(3):204-12

88 Pereira SS, Alvarez-Leite JI. Low-grade inflammation, obesity, and diabetes. Curr Obes Rep. 2014;3(4):422-31.

89 Costa M, Garmendia ML, Corvalán C, Reyes $\mathrm{M}$. The presence and duration of overweight are associated with low-grade inflammation in prepubertal Chilean children. Metab Syndr Relat Disord. 2016;14(9):449-54.

90 Seppä S, Tenhola S, Voutilainen R. Serum IL-1 receptor antagonist concentrations associate with unfavorable metabolic features in 12-year-old children. J Endocr Soc. 2018;2(8): 870-881.

91 Emerging Risk Factors Collaboration; Kaptoge S, Kaptoge S, Di Angelantonio E, Pennells L, Wood AM, White IR, et al. C-reactive protein, fibrinogen, and cardiovascular disease prediction. N Engl J Med. 2012;367(14): 1310-20.

92 Raqib R, Alam DS, Sarker P, Ahmad SM, Ara $\mathrm{G}$, Yunus $\mathrm{M}$, et al. Low birth weight is associated with altered immune function in rural Bangladeshi children: a birth cohort study. Am J Clin Nutr. 2007;85(3):845-52.

93 Bhuiyan AR, Srinivasan SR, Chen W, Azevedo MJ, Berenson GS. Influence of low birth weight on C-reactive protein in asymptomatic younger adults: the bogalusa heart study. BMC Res Notes. 2011;4:71.

94 Labayen I, Ortega FB, Sjöström M, Ruiz JR. Early life origins of low-grade inflammation and atherosclerosis risk in children and adolescents. J Pediatr. 2009;155(5):673-7.

95 Nordman H, Voutilainen R, Antikainen L, Jääskeläinen J. Plasma IL-1 receptor antagonist concentration has an inverse association with birth weight in prepubertal children. J Endocr Soc. 2018;2(3):232-9.

96 Çetin C, Baş F, Uçar A, Poyrazoğlu S, Saka N, Bundak R, et al. Comparative analysis of glucoinsulinemic markers and proinflammatory cytokines in prepubertal children born largeversus appropriate-for gestational age. Endocrine. 2014;47(3):816-24.

97 Mzayek F, Cruickshank JK, Amoah D, Srinivasan S, Chen W, Berenson GS. Birth weight was longitudinally associated with cardiometabolic risk markers in mid-adulthood. Ann Epidemiol. 2016;26(9):643-7.

98 Desai M, Jellyman JK, Ross MG. Epigenomics, gestational programming and risk of metabolic syndrome. Int J Obes. 2015;39(4):633-41. 
99 Costantino S, Mohammed SA, Ambrosini S, Paneni F. Epigenetic processing in cardiometabolic disease. Atherosclerosis. 2019; 281:150-8.

100 Gonzalez-Nahm S, Mendez MA, BenjaminNeelon SE, Murphy SK, Hogan VK, Rowley DL, et al. DNA methylation of imprinted genes at birth is associated with child weight status at birth, 1 year, and 3 years. Clin Epigenetics. 2018;10:90.

101 Huang RC, Garratt ES, Pan H, Wu Y, Davis EA, Barton SJ, et al. Genome-wide methylation analysis identifies differentially methylated CpG loci associated with severe obesity in childhood. Epigenetics. 2015;10(11):9951005.
102 Agha G, Hajj H, Rifas-Shiman SL, Just AC, Hivert MF, Burris $\mathrm{HH}$, et al. Birth weightfor-gestational age is associated with DNA methylation at birth and in childhood. Clin Epigenetics 2016;8:118.

103 Chiavaroli V, Cutfield WS, Derraik JG, Pan Z, Ngo S, Sheppard A, et al. Infants born large-for-gestational-age display slower growth in early infancy, but no epigenetic changes at birth. Sci Rep. 2015;5(1):14540.

104 Laitinen TT, Ruohonen S, Juonala M, Magnussen CG, Mikkilä V, Mikola H, et al. Ideal cardiovascular health in childhood - Longitudinal associations with cardiac structure and function: the special turku coronary risk factor intervention project (STRIP) and the cardiovascular risk in young Finns study (YFS). Int J Cardiol. 2017;230:304-309.

105 Fogelholm M, Nuutinen O, Pasanen M, Myöhänen E, Säätelä T. Parent-child relationship of physical activity patterns and obesity. Int J Obes Relat Metab Disord. 1999; 23(12):1262-8.
106 Lee PA, Chernausek SD, Hokken-Koelega AC, Czernichow P. International small for gestational age advisory board consensus development conference statement: management of short children born small for gestational age, April 24-October 1, 2001. Pediatrics. 2003;111(6 Pt 1):1253-61.

107 Das UG, Sysyn GD. Abnormal fetal growth: intrauterine growth retardation, small for gestational age, large for gestational age. Pediatr Clin North Am. 2004;51(3):639-54.

108 American College of Obstetricians and Gynecologists' Committee on Practice Bulletins: Obstetrics. Practice bulletin No. 173: fetal macrosomia. Obstet Gynecol. 2016; 128(5):e195-209. 